\title{
Corrigendum: A Recombinant Human Adenovirus Type 5 (H101) Combined With Chemotherapy for Advanced Gastric Carcinoma: A Retrospective Cohort Study
}

\author{
Ran Zhang, Yanxin Cui, Xin Guan and Xiang Jun Jiang* \\ Department of Gastroenterology, Qingdao Municipal Hospital, Qingdao University, Qingdao, China
}

Keywords: H101, chemotherapy, advanced gastric carcinoma, survival, response rate

\section{OPEN ACCESS}

Approved by:

Frontiers Editorial Office,

Frontiers Media SA, Switzerland

*Correspondence:

Xiangjun Jiang

drixj@163.com

Specialty section:

This article was submitted to

Gastrointestinal Cancers: Gastric and

Esophageal Cancers,

a section of the journal

Frontiers in Oncology

Received: 22 December 2021

Accepted: 17 January 2022

Published: 22 February 2022

Citation:

Zhang $R$, Cui $Y$, Guan $X$ and Jiang $X$ (2022) Corrigendum: A Recombinant Human Adenovirus Type 5 (H101)

Combined With Chemotherapy for

Advanced Gastric Carcinoma: A

Retrospective Cohort Study.

Front. Oncol. 12:841156.

doi: 10.3389/fonc.2022.841156

\section{A Corrigendum on}

A Recombinant Human Adenovirus Type 5 (H101) Combined With Chemotherapy for Advanced Gastric Carcinoma: A Retrospective Cohort Study

by Zhang R, Cui Y, Guan X and Jiang X (2021) Front. Oncol. 11:752504. doi: 10.3389/fonc.2021.752504

In the original article, there were three errors in the text.

Firstly, the dissolution of H101 was incorrectly stated. A correction has been made to Materials and Methods section, "Treatment Procedures", Paragraph 1:

"H101 $\left(-20^{\circ} \mathrm{C}\right.$, Shanghai Sunway Biotech, Shanghai, China) was then dissolved with normal saline to $30 \%$ of the estimated tumor volume at room temperature, was peritumorally injected via endoscopy according to the manufacturer's instructions, and these injections were repeated 21 days as one treatment cycle".

Secondly, the dose of $\mathrm{H} 101$ for patients with one lesion with a maximum diameter of $\leq 5 \mathrm{~cm}$ was incorrectly stated. A correction has been made to Materials and Methods section, "Treatment Procedures", Paragraph 2:

"The doses of H101 depended on tumor size and the number of lesions: (1) $0.5 \times 10^{12}$ virus particles (vp)/day (1 unit) for patients with one lesion with a maximum diameter of $\leq 5 \mathrm{~cm}$; (2) $1.0 \times$ $10^{12} \mathrm{vp} /$ day ( 2 units) for patients with one lesion with a maximum diameter of 5-10 $\mathrm{cm}$ or two lesions with a sum of the diameters of 5-10 cm; (3) $1.5 \times 10^{12} \mathrm{vp} /$ day (3 units) for patients with one lesion with a maximum diameter $>10 \mathrm{~cm}$ or $\geq$ three lesions; (4) for patients with two or more lesions, the dose of $\mathrm{H} 101$ for each lesion was further decided by the proportion and size of the different lesions. The number of cycles of $\mathrm{H} 101$ was determined according to the instructions for the use of H101 and patients' effect after injection. After injection of H101, renin $(0.1 \mathrm{mg} / \mathrm{ml})$ and thrombin (10-100 unit $/ \mathrm{mL})$ were sprayed to stop the bleeding". 
TABLE 2 | Short-term outcomes of H101, chemotherapy, and H101 combined with chemotherapy for advanced gastric carcinoma.

\begin{tabular}{lccc}
\hline & Group A $(\boldsymbol{n}=\mathbf{3 0})$ & Group B ( $\boldsymbol{n = 3 3 )}$ & Group C (n=32) \\
\hline Response assessment after treatment & & & $\boldsymbol{p}$-value \\
Complete response & $1(3.3 \%)$ & $2(6.1 \%)$ & $4(12.5 \%)^{*}$ \\
Partial response & $8(26.7 \%)$ & $9(27.3 \%)$ & $12(37.5 \%)$ \\
Stable disease & $10(33.3 \%)$ & $11(33.3 \%)$ & $10(31.3 \%)$ \\
Progressive diseases & $11(36.7 \%)$ & $11(33.3 \%)$ & $6(18.7 \%)^{*}$ \\
Disease control rate & $19(63.3 \%)$ & $22(66.7 \%)$ & 0.168 \\
Overall response rate & $9(30.0 \%)$ & $11(33.3 \%)$ & 0.941 \\
\end{tabular}

Group A, H101; Group B, chemotherapy; Group C, H101 combined with chemotherapy. ${ }^{*} p<0.05$ compared with group A.

Thirdly, the statistical comparison of CR and PD between group A and group C was incorrectly stated. A correction has been made to Results section, "Clinical Outcomes and FollowUp", Paragraph 1:

"Whereas, the combination of H101 injection with chemotherapy in group C $(n=32$ cases, four CRs and six PDs) was more effective than $\mathrm{H} 101$ injection alone in group A (all $p<0.05$, Table 2)."

The authors apologize for these errors and state that this does not change the scientific conclusions of the article in any way. The original article has been updated.
Publisher's Note: All claims expressed in this article are solely those of the authors and do not necessarily represent those of their affiliated organizations, or those of the publisher, the editors and the reviewers. Any product that may be evaluated in this article, or claim that may be made by its manufacturer, is not guaranteed or endorsed by the publisher.

Copyright (C) 2022 Zhang, Cui, Guan and Jiang. This is an open-access article distributed under the terms of the Creative Commons Attribution License (CC BY). The use, distribution or reproduction in other forums is permitted, provided the original author(s) and the copyright owner(s) are credited and that the original publication in this journal is cited, in accordance with accepted academic practice. No use, distribution or reproduction is permitted which does not comply with these terms. 